\title{
INDIGENCIA E SOCCORROS
}

Não se pense que ha, na lucta pelos auxilios aos pobres, o mais leve atáque ás idéas conservadores da actual sociedade. A propria Inglaterra, onde triumphou o "laisser faire", "laisser passer", o poder constituido vem, do mesmo modo que noutros paizes cultos, em auxilio dos que podem ser considerados indigentes, quer por "vicio", quer por "desgraça": doentes, victimas de accidentes de trabalho, velhos, invalidos, familias de mortos prematuramenter e faltos de serviço. Em nossa patria, muitas são as disposições legaes destinadas á protecção dos mais fracos.

Diversas e summamente difficeis, porém, são as questões sobre o mado por que devem ser attribuidos estes soccorros. Em geral, posso dizer mesmo "quasi unanimemente", são todos os que se interessam pelo assumpto contrarios ás esmolas dadas por particulares. Não comprehendo neste numero os auxilios dados a pessoas conhecidas por outras mais felizes. Normalmente o soccorro deve partir de associação.

0 1. ${ }^{\circ}$ problema é referente á administração desses gremios. A' medida que se foram tornando raros os conventos e outras instituições de caridade, desenvolveram-se as meramente leigas. Sem entrar na discussão sobre si aos particulares, si ao Estado cabe com vantagem a administraçáo de taes institutos, darei, sem argumentar, minha opinião sobre este ponto, opinião resultante de estudos e observação pessoal.

Entendo que a direcção, a administração deve ser exclusivamente do particular, e que ao Estado corre unicamente o dever de fiscalizar as instituições, e subven- 
cionar as "obras" com os impostos que perceber para soccorros publicos. E' possivel que me engane, mas continúo na convicção que sempre tive de que o Estado é pessimo administrador. Em nossa patria falta hoje a fiscalização. No antigo regimen, tinha o Brasil uma organização complicadisima de fiscalização entregue a magistrados. Fóra porém o que constava de testamento, nada mais attrahia, ao menos desde quei entrei para o fôro, as vistas dos juizes: a fiscalização era pois imperfeitissima.

Actualmente a necessidade dessa fiscalização se faz sentir em muitas instituições do interior do nosso Estado. $\mathrm{Si}$ é certo que, na capital, toda a gente, sem discrepancia, unanimemente, a uma só voz, louva a abnegaçã́o e desprendimento dos philanthropos que acodem a todas as necessidades dos indigentes, na maternidade, na gotta de leite, nos hospitaes, nos albergues nocturnos, nos innumeros estabelecimentos de educação da infancia desvalida ou abandonada e até nos asylos para velhos, não é menos vendade que, em certos pontos do interior, têm apparecido sérias queixas contra a applicação dos fundos arrecadados de pessoas caridosas. Autoridades fiscalizadoras pois se tornam indispensaveis.

Como disse eu, porém, em meu artigo anterior, havendo benemeritos que estão a idear até restaurantes para os empregados do commercio que não podem ir ao lar tomar as suas refeições sem sacrificio do tempo em seus trabalhos (instituição optima), ninguem tambem contestará que, tendo o particular já dado tudo quanto lhe era possivel, resta ao Estado cumprir seu dever: subvencionar estes institutos que hoje já são insufficientes para a população sempre crescente desta capital. Força é dizer: o Estado não correspondeu ao que se deveria esperar delle.

$\mathrm{Na}$ organização dos institutos, ha innegavelmente alguns de maior e outros de menor importancia quanto ao mớdo de organização. E' assim que um asylo para velhos, comquanto tão exigido pela solidariedade social 
quanto as demais "obras", não requer os mesmos cuidados que um recolhimento para menores de cuja educação (coisa summamente difficil) depende a diminuição dos velhos indigentes em tempos vindouros. Foi porque os nossos avós não curaram devidamente da criação e da educação dos menores indigentes no tempo antigo que a actual sociedade está luctando com tão elevado "numero de velhos a pesar sobre ella.

Até aqui tenho feito referencia á organização das instituições, defendendo as seguintes theses: que o espirito de humanidade é muitissimo accentuado nesta capital; que o augmento rapido da população reclama todavia imprimirse muito maior desenvolvimento ás "obras" que têm vida neste populosissimo centro; que a administração de institutos desse genero deve ser exclusivamente feita por particulares; e que ao Estado cabe o dever de auxiliar esse esforço, filho da solidariedade humana, com o producto dos impostos lançados sobre o povo e de fiscalizar a applioação dos recursos por elle e pelos particulares fornecidos a taes "obras"

Parece-me, pelo que tenho lido em livros, particularmente nos de Gide, Schmoller, Wagner, Leroy, Beaculieu e outros, pelo que ouvi de "rarissimos" patricios nossos que têm peregrinado pela velha Europa interessando-se por este aspecto social, que o $10^{\circ}$ paiz quanto a soccorros publicos é a França, seguida de perto pela Allemanha. Da Inglaterra' sei que possue optimas leis sobre a materia, mas infelizmente o pauperismo lá se mantem em aspecto verdadeiramente assustador, em vista da pessima organização do trabalho que desde muitos seculos ha naquelle paiz. Para dizer o que é a França quanto a auxilios racionalmente dados, intelligentemente fornecidos, basta lembrar 0 que foi a lucta por ella emprehendida para a recrganização do trabalho após a grande guerra, e referir, que, conforme se mostra no fasciculo da "Revista dos Dois Mundos" sahido a 15 de Fevereiro deste anno, á pag. 952, 
está o governo francez a pagar 12 fr. e .50 cent. aos operarios que não têm trabalho. Querem os commumistas que recebam esses desoccupados o mesmo que os que se acham trabalhando, ao que se oppõe o presidente julgando exceder isto o limite do devido pelo Estado a quem não pód encontrar serviço.

$\mathrm{Na}$ oganização da assistencia aos necessitados, uma idéa foi, ha tempo, pelo desembargador Clementino de Castro apresentada em nossa capital. A proposta muito digna é, no meu modo de pensar, do apoio de todas as classes. Refiro-me ás organizações de gremios por clas. ses. Exemplos tornarão claro meu mado de apreciar o caso. Foi lembrado pelo desembargador Clementino que os numerosos jornaes e as varias revistas se cotizassem, formando associações entre seus directores ou gerentes, para accudirem as necessidades desses infelizes que, sob o sol ardente ou debaixo de chuvas torrenciaes, levam a folha assignante, ou ao freguez, esses portadores humildes e obscuros do pão espiritual com que se alimenta a intelligencia dos nossos concidadãos. Não será muito, dizia a pesso: que teve esta idéa, organize a imprensa dormitorios para aquelles de seus auxiliares que não têm á noite onde repousar das fadigas do dia; e que sustente um modestissimo restaurante onde: encontrem alimento limpo e por preço ao alcance da bolsa modestissima da tribu nomade que tanto serviço presta á disseminação de bôas idéas no seio do nosso povo. Nem será muito pedir propor a creação de uma caixa que accuda os que forem victimas de accidentes no exercicio da profissão. Darei um exemplo. Durante o estado de sitio, indo no Rio de Janeiro em um caminhão um entregador de jornaes levar á estação da estrada de ferro alguns numeros do "Jornal", foi por um soldado intimado a parar. Como, em consequencia do barulho das rodas e do motor, não tivesse ouvido a ordem, não suspendeu a marcha. Atirado, como si fôra uma féra, cahiu morto. Tinha o soldado direito de tal fazer, á guiza de 
guarda do palacio de Francia? Poderia matar um homem mesmo que fosse este um delinquente e fugisse? De nenhum modo. $\mathrm{O}$ art. 182 de nosso Codigo do Processo, a reforma de 1871! e o Codigo Penal de 1890 nenhuma duvida deixam a respeito: o delicto de assassinato não póde ser escusado em taes circumstancias. Mas não é o que me interessa no momento: depois do inquerito Niemeyer, outros crimes serão objectos da attenção da actual policia. 0 que me interessa agora é a situação precaria em que pro vavelmente ficou a familia da victima, desapparecida nas mesmas circumstancias de tantos outros cidadãos para. guayos baleados pelas sentinellas do dr. Francia. Si houvesse uma caixa entre os jornalistas, seria corrigido esse mal. Não se me diga que esses accidentes raramente se dão com os portadores de jornaes. Posso assegurar que correm grande risco em todo o interior do Estado, e que. aqui mesmo não sei acham muito seguros, quando a policia volta os olhos ferozes contra alguma folha mais livre em seus conceitos.

Bem sei que ha vendedores de jornaes que foram felizes, e até constituiram fortuna, mas são rarissimas excepçôes. E' bom, de passo, consignar que, por um bellissimo movimento de solidariedade, fundou, ha pouco tempo, a imprensa os asylos para os velhos jornalistas invalidos.

0 que digo da imprensa, a que sempre estive ligado (e a boa caridade começa por casa) devo dizer das industrias manufactureiras e da agricola. Escolas nas fazendas, fundadas pelos proprietarios, pharmacia a distribuir men dicamentos gratuitamente aos trabalhadores que o chefe do estabelecimento conhece como sendo "verdadeiramente" necessitados, auxilios ás familias dos que succumbem no trabalho antes que tenham constituido um peculio, e cutras fórmas de assistencia, eis o que era "nada" para um grupo de fazendeiros em um dado bairro, eis o que era "tudo" para os necessitados, que são muitos. Nas grandes cidades, e particularmente nesta capital, quão facil 
seriam essas uniōes entre os industriaes de fabricas de tecidos, entre os negociantes atacadistas ou retalhistas de um certo ramo em favor de seus empregados, entre os proprietarios de hoteis em prol dos seus serviçaes.

Esta idéa, que não é minha (repetirei mais uma vez), resolve uma das maiores difficuldades da assistencia, e vem a ser de distinguir o "necessitado" do "vadio". Os chefes de uma classe estão em muito melhores condições para conhecerem os verdadeiros necessitados do que os philanthropos que distribuem soccorros á massa geral dos indigentes: estes tratam com um grande numero, aquelles com limitadissimo grupo.

Já disse eu, linhas acima, que muitas providencias devem ser tomadas para que seja diminuido o numero dos pobres. A boa organização do trabalho é a mais importante. Darei um exemplo. E' sabido que um dos problemas para attender aos clamores dos sem trabalho é derivar das cidades para a agricultura o excesso de operarios. Em 1917, quando a crise nas industrias urbanas se accentuou em nosso paiz, em consequencia da grande guerra, houve nesta capital a parede dos operarios que foi considerada, não como sendo um "episodio da questão social", mas sim como não passando ide um "caso policial" Recordam-se todos como foram tratados os operarios paulistas, homens ordeiros, e que continuam até hoje ao lado das autoridades. Ora, como bem disse, naquelle anno funesto, a imprensa, uma vez entrado o Brasil no numero dos paizes de industria urbana, força nos é attender ás necessidades do operariado, com medidas que têm sido adoptadas por outros paizes dados á industria manufactureira.

Acredito que a crise de excesso de braços foi passageira, filha de circumstancias momentaneas. Mas, si continuar a congestão de operarios em nossos centros populosos, si ficarmos nas condiçóes da Inglaterra, cujos operarios não sahem das cidades, e constituem o exercito dos sem trabalho, que fazer? Em artigo que publiquei pouco depois 
da parede de operarios de 1917, subordinando meu trabalho ao titulo de "Rumo ao campo", mostrei que não é possivel obrigar (sem tyrannia ou violencia) os operarios de industrias urbanas a irem para o campo, para a roça. (De modo diverso pensam muitos dos nossos fazendeiros: entendem que é caso do uso dos conhecidissimos processos policiaes). Sustentava eu que os operarios que não conhecem os trabalhos dos campos necessariamente terão horror á vida agricola. Disseminar pois o ensino profissional agricola, eis o remedio, no meu modo de entender. Meu artigo passou aqui despercebido. Teve entretanto o applauso de um dos nossos mais entendidos em assumptos desse genero. Refiro-me ao meu distincto collega dr. Zeferino de Faria, que tem sido representante do Brasil em varios congressos sobre assistencia ás classes indigentes.

Sem duvida, podem ser facilmente reduzidos os operarios á obediencia, podem ser esmagados, como o foram, em 1917, nesta capital, e egualmente, por tantos annos, na Russia, e of são hoje na Inglaterra, mas será isto desejavel?

João Arruda. 